\title{
On the soldering techniques of gold objects from the Boma site, Xinjiang, China
}

\author{
Fan Yang a , Thilo Rehren ${ }^{b, c}$, Ping Kang ${ }^{d}$, Kunlong Chen ${ }^{\text {a }}$
}

a) Institute of Historical Metallurgy and Materials, University of Science and Technology Beijing, 100083 Beijing, China

b) Science and Technology in Archaeology and Culture Research Center, The Cyprus Institute, Nicosia, Cyprus

c) UCL Institute of Archaeology, WC1H OPY London, UK

d) Museum of Ili Kazakh Autonomous Prefecture, 835000 Yining, China

\section{Abstract}

The soldering techniques used in ancient goldwork are of great interesting for scholars from various disciplines. In this paper, the soldering techniques of the 3 to 5 century CE gold artefacts from the Boma site in Xinijang are investigated based on micro-analysis of crosssection samples. The results show that Au-Ag-Cu ternary alloy with high silver and copper content was used as solder material for connecting gold wire onto the arm armor, while copper salts bonding was use for the granulation of finger ring and scabbard. The abnormal slight compositional differences at the joining areas of the Boma granulation samples reminds us their complicated heat treatment, a crucial aspect for the understanding of ancient goldsmithing to which more attention needs to be paid.

\section{Keywords:}

Ancient goldwork

Joining technique

Solder material

Copper salt bonding

Heat treatment 


\section{Introduction}

Ancient goldwork has been an important source of knowledge on the history of art, technology, trade and cultural interaction[1]. While studies on typology, stylistics, and iconography are essential for understanding aesthetics, function and social meaning of an object, scientific analysis-based research can provide much information of its material, fabrication techniques and provenance [2,3]. Ancient gold objects, especially jewelry and other decorative artefacts often consist of many different parts. To successfully join these parts together, which often include tiny granules, wires and sheets, sufficient knowledge of physical and chemical behaviors of different materials, fine craftsmanship skill and sophisticated control of heating were inevitably required. In this light, various delicate joining techniques, including welding and soldering are indeed among the most impressive of the ancient goldsmith's remarkable achievements, and have become a longstanding hot topic attracting much research interest from art historians, scientists and archaeologists [4-6] .

Despite the diverse terminology used by different scholars, it is generally considered that three main types of welding/soldering techniques were used for gold working in antiquity, namely copper salt bonding (welding or solid-state diffusion), brazing or hard-soldering (adding a metal alloy) and autogenous fusion welding (sintering) [4, 6-8]. Facilitated by micro-analytical methods such as Scanning Electron Microscopy with Energy Dispersive X-Ray Spectrometry (SEM-EDS), the different processes can be distinguished by detecting the changes of concentrations of copper and silver in the contact zones and the joined parts [7, 9]. It is no doubt that the use of non-destructive methods is very informative for analyzing ancient gold work $[8,10]$, however, in appropriate circumstances direct observation on cross sections can provide metallographic information reflecting the heat treatment history of the object that is otherwise not accessible $[6,7,9]$. More importantly, a confident determination of compositional variation of the contact zones from cross section sample is sometimes crucial for distinguishing different joining techniques. It is not unusual that archaeological gold objects often have received repeated heat treatment during their manufacturing and experienced selective corrosion and surface contamination during usage and burial history, which could have altered their surface composition [11-13]. In this paper, we present analytical results of archaeological gold objects from the Boma site in Xinjiang, China. By identifying the joining processes used in different objects, it is expected to increase our understanding of ancient goldwork techniques and the interpretation of relevant analytical data.

\section{Materials and Methods}

In late 1990s, numerous objects made of gold, silver, glass and textile were accidentally discovered during road construction at the Boma site in Zhaosu County, Xinjiang. (Figure 1) [14]. Despite the remarkable assemblage of elegant artefacts, archaeological information regarding the Boma site is very limited, and the context, date and cultural attribute of the Boma finds are controversially discussed [14-16]. According to the later archaeological surveys in the region and typological studies on the objects, this paper is inclined to accept the interpretation that the Boma finds belong to a noble burial of the ancient Wusun group dated from the 1st century BCE to the 5th century CE, or more specifically around the 3rd to 5th century CE $[14,16,17]$.

Three small pieces of detached fragments of gold objects from the Boma collection were available for analysis. Samples BM02 and BM10 are fragments of granulation decoration parts from a finger ring and a scabbard, respectively. Sample BM13 is a gold wire connected with a small piece of gold sheet from an arm armor (Figure 1). Detailed description of the artefacts can be found in $[14,16]$. 


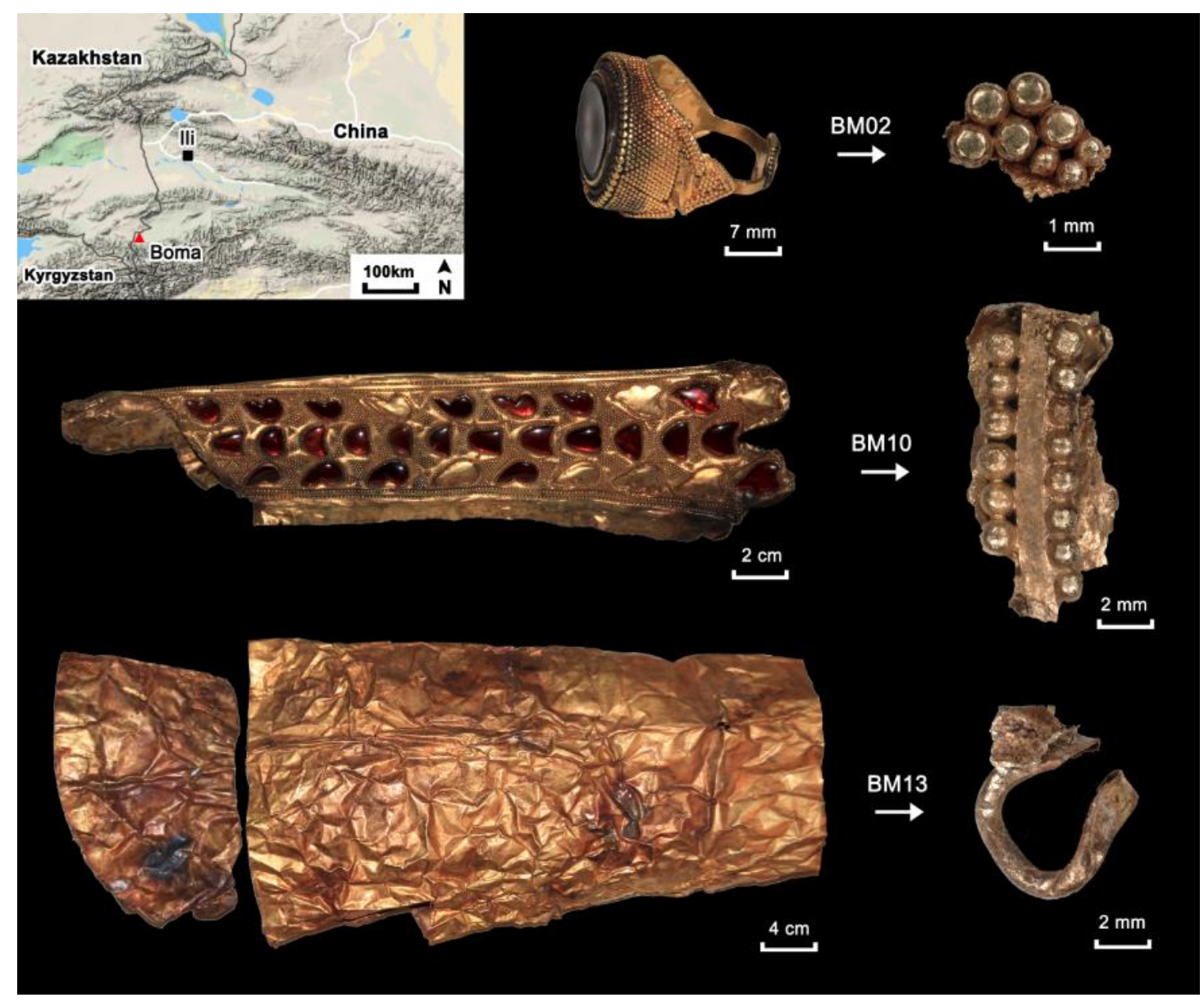

Fig. 1 The location of the Boma site and the objects analyzed in this paper

All analytical work presented in this paper has been carried out at the University of Science and Technology Beijing (USTB). The samples were firstly studied using a Keyence VHX-600 digital microscope to record the manufacturing traces and to measure the size of various parts. Separated pieces were cold mounted with epoxy resin in a certain direction and were ground and polished to reveal fresh cross-sections of the joining areas. For chemical composition and microstructure analysis, a Tescan Vega 3 XMU SEM equipped with a Bruker 610M EDS analyzer was used. The analytical conditions of SEM-EDS were set at an acceleration voltage of $20 \mathrm{kV}$, a working distance of around 15 $\mathrm{mm}$, and an acquisition time of 60s. Line scanning analysis has been carried out using a Shimadzu $1720 \mathrm{H}$ Electron Probe Microanalyzer (EMPA) at $15 \mathrm{kV}$ acceleration voltage and $30 \mathrm{nA}$ beam current. For metallographic examination, the samples were etched and observed with te Keyence VHX-600 digital microscope under coaxial cone light.

\section{Results}

The full results of SEM-EDS analysis of the cross-section samples are provided in the Table 1 and Figure 2. All three objects are made of gold with notable amount of silver and copper. While the composition shows clear difference among the three objects, there is hardly any variation between different jointed parts (except the soldering areas) of the same object. The consistent concentration of $\mathrm{Ag}$ and $\mathrm{Cu}$, and especially the high Ag content of BM13 (> $20 \mathrm{wt} \%$ ) suggest a possible control of alloy recipes that the same batch of gold metal was used to make the different parts of a single object, and different batches for different objects. So far, however, whether the compositional variation between these objects reflects their origin from different workshops, or just the variability of different gold batches available within a single workshop is hard to decide. Overall, the silver content is consistent with typical natural contents of unrefined gold from placer deposits, particularly for the relatively low 
silver concentrations of $\mathrm{BMO} 2$ and $\mathrm{BM} 10$, but an origin from hard rock mining cannot be excluded, particularly for the much higher silver contents in BM13. The copper content, in contrast, is too high for natural gold; here, an artificial addition of copper has to be considered.

Table 1. SEM-EDS results of gold artefacts from Boma (see Figure 2 for the location of analysis)

\begin{tabular}{|c|c|c|c|c|c|c|c|c|c|c|c|}
\hline \multirow{2}{*}{ Sample } & \multirow{2}{*}{ Area } & \multicolumn{3}{|c|}{ Composition wt\% } & \multirow{2}{*}{ Remark } & \multirow{2}{*}{ Sample } & \multirow{2}{*}{ Area } & \multicolumn{3}{|c|}{ Composition wt\% } & \multirow{2}{*}{ Remark } \\
\hline & & $\mathrm{Au}$ & $\mathrm{Ag}$ & $\mathrm{Cu}$ & & & & $\mathrm{Au}$ & $\mathrm{Ag}$ & $\mathrm{Cu}$ & \\
\hline \multirow{10}{*}{ BM02 } & 1 & 91.2 & 6.5 & 2.3 & \multirow{3}{*}{ granule } & \multirow{9}{*}{ BM10 } & 3 & 84.9 & 10.7 & 4.4 & strip \\
\hline & 2 & 92.1 & 6.2 & 1.7 & & & 4 & 85.4 & 10.2 & 4.4 & \multirow{3}{*}{ sheet } \\
\hline & 3 & 92.0 & 6.4 & 1.6 & & & 5 & 84.6 & 10.9 & 4.5 & \\
\hline & 4 & 90.6 & 5.8 & 3.6 & \multirow{3}{*}{ sheet } & & 6 & 84.3 & 11.2 & 4.5 & \\
\hline & 5 & 91.0 & 6.4 & 2.4 & & & 7 & 84.4 & 10.2 & 5.4 & \multirow{5}{*}{$\begin{array}{c}\text { soldering } \\
\text { area }\end{array}$} \\
\hline & 6 & 92.0 & 6.4 & 1.6 & & & 8 & 84.5 & 10.7 & 5.0 & \\
\hline & 7 & 91.4 & 6.3 & 2.4 & \multirow{4}{*}{$\begin{array}{c}\text { soldering } \\
\text { area }\end{array}$} & & 9 & 84.3 & 10.7 & 5.0 & \\
\hline & 8 & 90.1 & 6.3 & 3.6 & & & 10 & 84.5 & 10.6 & 4.9 & \\
\hline & 9 & 90.6 & 5.6 & 3.5 & & & 11 & 84.5 & 10.0 & 5.5 & \\
\hline & 10 & 91.6 & 5.8 & 2.6 & & \multirow{3}{*}{ BM13 } & 1 & 76.1 & 21.9 & 21.9 & wire \\
\hline \multirow{2}{*}{ BM10 } & 1 & 84.8 & 10.6 & 4.6 & \multirow{2}{*}{ granule } & & 2 & 76.1 & 21.9 & 21.9 & sheet \\
\hline & 2 & 84.7 & 10.8 & 4.5 & & & 3 & 49.8 & 42.7 & 42.7 & solder \\
\hline
\end{tabular}

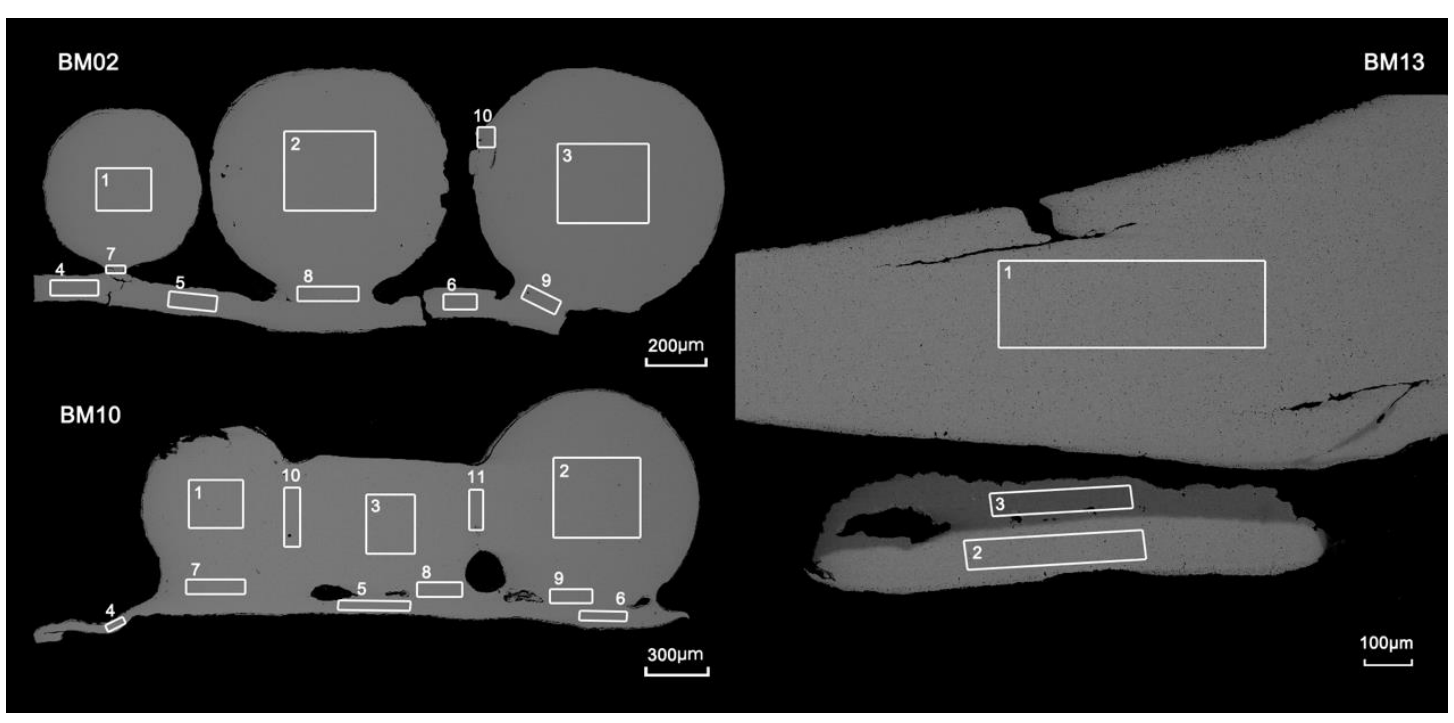

Fig 2. BSE image overview of cross-section samples of Boma gold (Analytical areas in Table 1 are marked. Note the darker appearance of solder material in BM13)

Compositional analyses at the joining areas show distinct features among the three samples. For $\mathrm{BM} 02$ and BM10, the results indicate slight but consistent increase of copper in the joining zones between granules, base sheets and the gold strip (Table 1, Figure 2). The count rate of copper content obtained by the EPMA line scanning analyses demonstrate the same trend (Figure 3). Much more significant change of composition at the joining area is observed from BM13. The notable higher content of relatively light elements (Ag $43.7 \mathrm{wt} \%$ and $\mathrm{Cu} 8.1 \mathrm{wt} \%$ ) results in a separated darker phase showing clear boundary with the joined base sheet (Ag 21.6 wt\%, Cu 1.9 wt \%) in the BSE image (Table1; Figure2). 


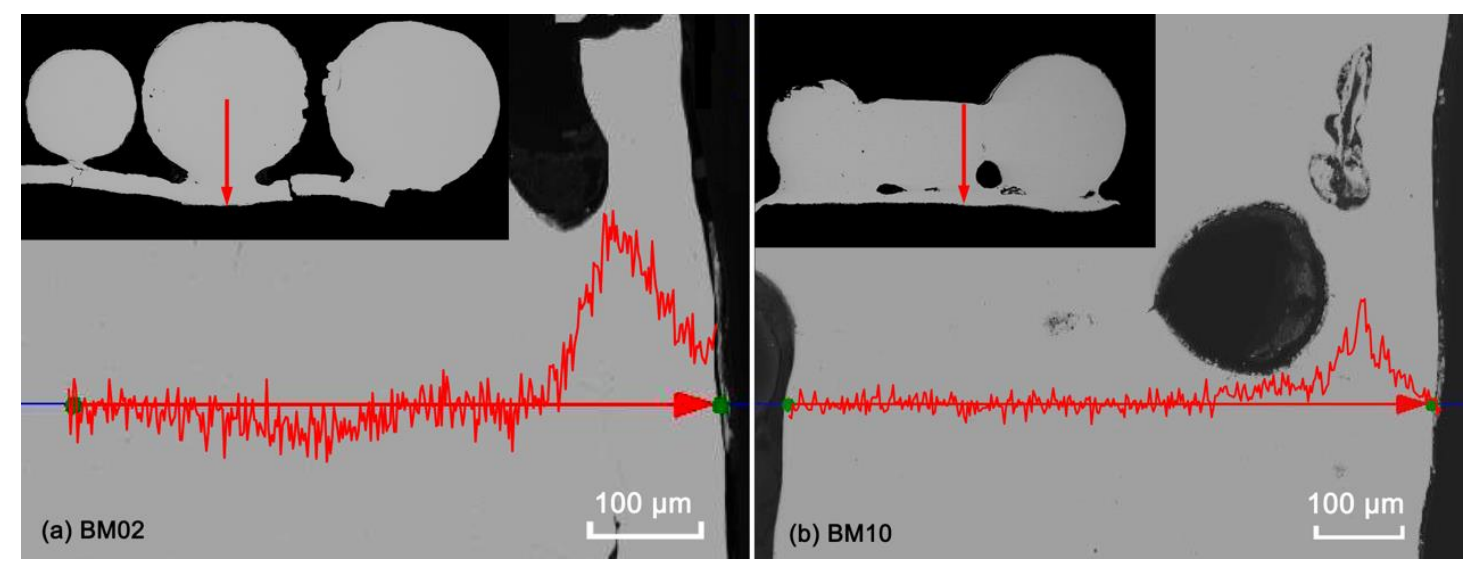

Fig 3. EPMA line analysis of BMO2 (a) and BM10 (b) showing the increasing of copper counts at the joining areas between the granule and the base sheet

According to the metallographic examination, all individual parts of the three samples, including granules, base sheets, strip and wire show typical microstructure of equiaxial grains (Figure 4). At the same time, the differences of grain morphology and size indicate that their working and heating experiences are different from each other. The large hexagonal crystals of BM02 and BM10 suggest a long duration of high temperature and/or slow cooling rate which facilitated the growth of recrystallized grains (Figure $4 a, b$ ). Regarding the joining areas, there is no evident discontinuity between different parts and similar hexagonal crystals are observed (Figure 5a). On the other hand, the small and twinned grains of gold wire from BM13 reflect intense working deformation and repeated annealing (Figure 4d). The dendritic structure in the joining zone is sharply different from the wire and the sheet. This "as-cast" structure, together with the presence of rounded porosity indicates an in-situ solidification of the soldering metal from the liquid state (Figure 5b).

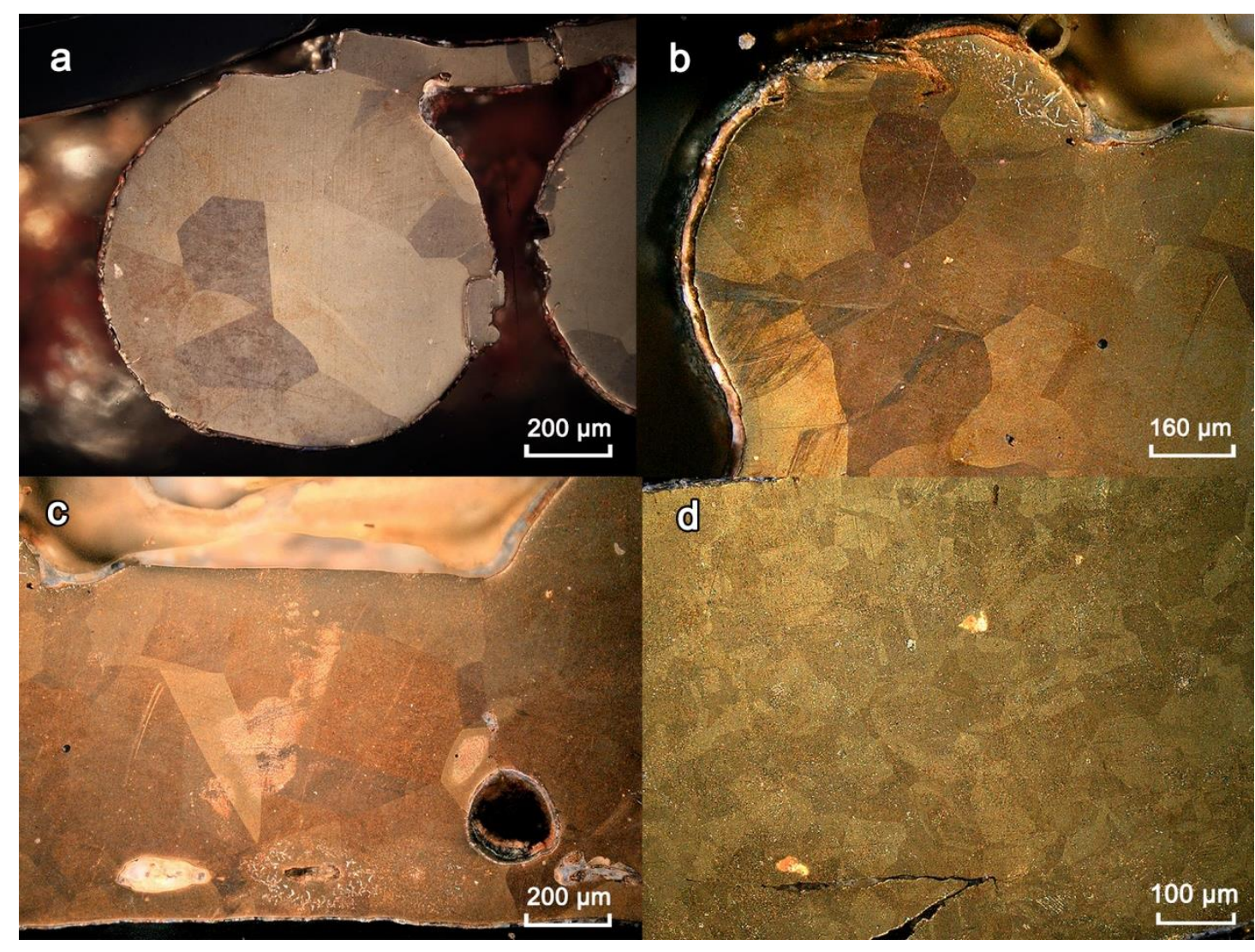

Fig 4. Photomicrographs of the different joined parts showing the large equiaxial grains of the 
granulation (a: BM02's granule, b and c: BM10's granule and strip) and the fine twinned structure of the gold wire from BM13 (d). Etched with...?

What is this thin sheet peeling off from the granules (Fig. 5a, b)? I think we looked at it in the SEM for sample BM02 and found it difficult to resolve, but here it seems even more clear in BM10, as a separated sheet / skin / layer? We were considering at the time a surface leaching effect, either from pickling to remove excess copper after the granulation / soldering, or due to long burial. Any new insights into this phenomenon?

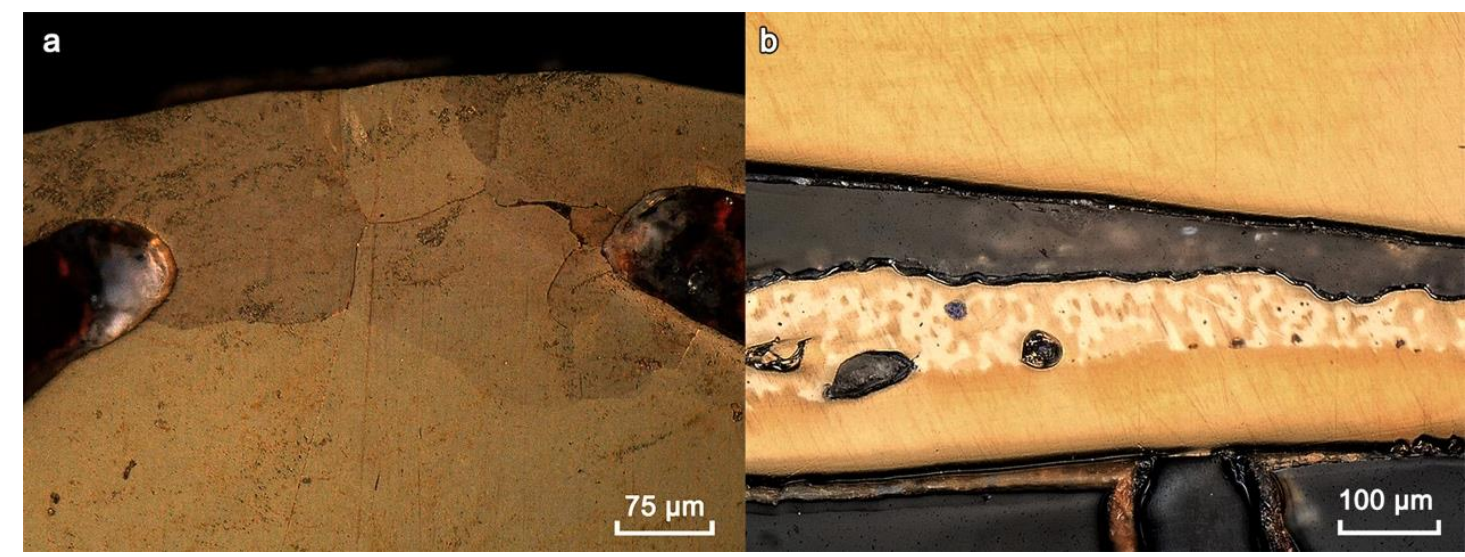

Fig 5. Photomicrographs of the joining areas. Note (a) the continuous annealing microstructure in sample BM02, and (b) the dendritic grains of solder material in sample BM13.

\section{Discussion}

On the basis of the analytical results, it is clear that different welding/soldering techniques had been used during the fabrication of the Boma gold artefacts. The evident change of chemical composition at the joining zone of BM13 indicates that a soldering (or soft brazing) process with added filler metal (solder) was applied to connect the gold wire and sheet. According to the Au-Ag-Cu ternary diagram, the increased concentration of $\mathrm{Ag}$ and $\mathrm{Cu}$ in the solder metal will lower its melting point to around $920^{\circ} \mathrm{C}$, creating a temperature difference from the melting point of the parts to be jointed (about $1030^{\circ} \mathrm{C}$ ) [18]. Such a temperature interval of more than $100^{\circ} \mathrm{C}$ would allow the ancient goldsmith to melt the solder metal while the jointed parts were still in solid state. Localized heating methods such as a blowpipe could have been used in the case of BM13, considering the very small area of the melt. This suggestion is also supported by the dendritic grains and the trapped porosity in the solder metal, which often reflects a condition of direct solidification without further annealing.

In samples BM02 and BM10, compared to the joined parts (granules, sheets and strip) the joining areas were found to have a slight but consistently increased concentration of $\mathrm{Cu}$ and a continuous structure of equiaxial grains which is almost identical with the microstructure of an experimental sample of copper salt bonding reported by Scrivano et al [6]. Based on these results, it is plausible to suggest that copper salt bonding had been used for the fabrication of these granulation artefacts.

The copper salt bonding method used in antiquity has been discussed extensively by scholars from various disciplines. Although it is broadly accepted to be an in-situ reduction of copper minerals into metallic copper which facilitats the joining of different parts in a minute contact area, there are different understandings regarding the actual bonding mechanism and chemical-physical reactions between the soldering area and the contacting parts. Some scholars interpreted it as a result of solidstate diffusion process $[6,8]$, while the others considered that a fluid melt had been achieved as the additional copper will lower the melting point of gold alloy at the contact zones [7, 9]. It is undoubted that the materials used and manufacturing conditions varied in different regions and periods, and both the suggested scenarios could have occurred. In addition, according to our data, the slight differences of copper concentration at joining areas (around $1 \mathrm{wt} \%$ ) of the Boma samples seems quite 
unusual compared to the more notable increasing of copper (normally greater than $5 \mathrm{wt} \%$ ) as reported in other cases of copper salt bonding, including both archaeological and experimental materials $[6,9]$. This observation further underlines the many possible variations of the copper salt joining technique during its long history of application in goldsmithing.

Heating conditions during the soldering operation and the following manufacturing process will affect the soldering material which leaves detectable features such as the distribution of different elements and microstructure [18]. This is one of the fundamental premises for the discrimination of different joining techniques on the basis of scientific analysis [7]. It is not difficult to image that different artefacts could have experienced different heat treatment history, which might explain the aforementioned discrepancies in various examples of copper salt joining methods. The localized heating operation such as a fire blowpipe (or a gas torch as used in many experimental research) is often characterized by the quick rise and fall of temperature $[12,19]$. This is likely to result in a more significant compositional variation at the joining zone due to the limited time for the diffusion of copper. If a sufficiently high temperature had been reached, the newly formed alloy would melt and resulted in a dendritic microstructure [9]. On the other hand, if the object was heated in its entirety in an open fire or even in a closed furnace/oven, a longer duration at high temperature could have occurred, resulting in longer diffusion and reduced compositional heterogeneity. Alternatively, in particular the more complex artefacts might have been heated repeatedly, which would also facilitate the homogenizing of composition in different parts and result in an annealing microstructure due to recrystallization [13]. In our view, the later situation might explain the unexpectedly low differences of copper content at the joining areas of the Boma granulation samples (BM02 and BM10), as well as the large grain size of the hexagonal crystals. Considering the overall small size of the granules and the thinness of the sheet, such a longer heat treatment would not only reduce the difference in copper content between the contact area and the joined parts, but logically also lead to an overall increase of copper content throughout the object's constituent parts, as seen in the analytical results.

\section{Conclusion}

The micro-analysis revealed that two different joining techniques were used for the Boma gold objects. The gold wire was soldered onto the arm armor by using a ternary alloy of $\mathrm{Au}-\mathrm{Ag}$-Cu with high $\mathrm{Ag}$ and $\mathrm{Cu}$ concentration. The melting point of the soldering material is about $100{ }^{\circ} \mathrm{C}$ lower than that of the joined parts. The consistently higher copper concentration at the joining areas between the granules and their support indicates that copper salt bonding was used for granulation. It is suggested that the low level of differences in composition, the elevated copper content compared to the otherwise natural gold composition, and the large recrystallized equiaxial grains in the bonding areas are due to repeated heating of the objects during their manufacturing process. The various heating methods and complicated heating operations of ancient goldsmithing are worth more attention in the future.

\section{Acknowledgment}

Funds (incl. for me to come to USTB), Marcos, Siran and Jianli. 


\section{References}

[1] R.W. Boyle, Gold: history and genesis of deposits, Van Nostrand Reinhold, New York, 1987.

[2] G. Morteani, J.P. Northover, Prehistoric gold in Europe: mines, metallurgy and manufacture, Kluwer Academic Publishers, Dordrecht, 1995.

[3] M. L. Vitobelo, Th. Rehren, A Quest for Authenticity, Institute for Archaeometallurgical Studies, London, 2009.

[4] D. L. Carroll, A classification for granulation in ancient metalwork, American journal of archaeology, 78 (1974) 33-39.

[5] G. Demortier, The Soldering of Gold in Antiquity, MRS Proceedings, 123 (1988) 123-193.

[6] S. Scrivano, B. Gómez Tubío, I. Ortega-Feliu, F. Ager, A. Paul, M. Respaldiza, Compositional and microstructural study of joining methods in archaeological gold objects, X - Ray Spectrometry, 46 (2017) 123-130.

[7] P. Parrini, E. Formigli, E. Mello, Etruscan granulation: Analysis of orientalizing jewelry from Marsiliana d’Albegna, American Journal of Archaeology, 86 (1982) 118-121. [8] G. Demortier, LARN experience in nondestructive analysis of gold artifacts, Nuclear Instruments Methods in Physics Research Section B: Beam Interactions with Materials AtomsNuclear Instruments, 14 (1986) 152-155.

[9] E. Mello, P. Parrini, E. Formigli, Etruscan filigree: welding techniques of two gold bracelets from Vetulonia, American Journal of Archaeology, 87 (1983) 548-551.

[10] S. Scrivano, I. Ortega-Feliu, B. Gómez-Tubío, F. J. Ager, M. L. de la Bandera, M. A. Respaldiza, M. A. Ontalba-Salamanca, Non-destructive micro-analytical system for the study of the manufacturing processes of a group of gold jewels from "El Carambolo" treasure, Radiation Physics and Chemistry, 130 (2017) 133-141.

[11] A. J. Forty, Corrosion micromorphology of noble metal alloys and depletion gilding, Nature, 282 (1979) 597-598.

[12] D. Loepp, A. Maass, Experimental replication of a granulated gold bead from an ancient tomb at Bat, Oman, Metalla, 23 (2017) 29-38.

[13] J. Wolters, Granulation: a re-assessment of an ancient craft, Endeavour, 6 (1982) 29 .

[14] Y. An, Gold, silver and other items unearthed from an ancient tomb in Zhaosu County, Ili, Xinjiang, Wenwu, (1999), no. 9, 4-15. (in Chinese)

[15] Y. Lin, The Byzantine Element in the Turkic Gold Cup with the Tiger Handle Excavated at Boma, Xinjiang, The Silk Road, 5 (2008) 20-26.

[16] L. Deng, D. Bi, Reconsideration of the chronology and ethnic attribute of the Boma tomb in Xinjiang, Wenwu Chunqiu, (2011), no. 1, 18-24. (in Chinese)

[17] H. Lü, The Study on the early burials in the western Himalaya Region Kaogu Xuebao, (2015), no. 1, 1-34. (in Chinese)

[18] D. A. Scott, R. Schwab, Metallography in Archaeology and Art, Springer, 2019.

[19] S. Scrivano, B. Gómez-Tubío, I. Ortega-Feliu, F. Ager, A. Moreno-Suárez, M. Respaldiza, M. De la Bandera, A. Marmolejo, Identification of soldering and welding processes in ancient gold jewelry by micro - XRF spectroscopy, X-Ray Spectrometry, 42 (2013) 251-255. 